\title{
Extracolonic cancer risk in Dutch patients with APC (adenomatous polyposis coli)-associated polyposis
}

\author{
Zeinab Ghorbanoghli, ${ }^{1,2}$ Barbara AJ Bastiaansen, ${ }^{3}$ Alexandra MJ Langers, ${ }^{1}$ \\ Fokko M Nagengast, ${ }^{4}$ Jan-Werner Poley ${ }_{1}{ }^{5}$ James CH Hardwick, ${ }^{1}$ Jan J Koornstra, ${ }^{6}$ \\ Silvia Sanduleanu, ${ }^{7}$ Wouter H de Vos tot Nederveen Cappel, ${ }^{8}$ Ben JM Witteman, ${ }^{9}$ \\ H Morreau, ${ }^{10}$ Evelien Dekker, ${ }^{3}$ Hans FA Vasen ${ }^{1,2}$
}

For numbered affiliations see end of article.

\section{Correspondence to}

Dr Hans FA Vasen, Department of Gastroenterology and Hepatology, Leiden University Medical Centre, Rijnsburgerweg 10, 2333 AA Leiden, The Netherlands; hfavasen@stoet.nl

Received 19 January 2017 Revised 12 April 2017 Accepted 13 April 2017 Published Online First 10 May 2017

\section{CrossMark}

\section{ABSTRACT}

Background Screening of patients with familial adenomatous polyposis (FAP) have led to a substantial reduction in mortality due to colorectal cancer (CRC). Recent guidelines suggest that surveillance of nonintestinal malignancies should also be considered in those patients. However, the value of these surveillance programmes is unknown. The aims of this study were (1) to assess the occurrence of extracolonic malignancies in a large series of adenomatous polyposis coli (APC) mutation carriers and (2) to evaluate the causes of death. Methods All APC mutation carriers were selected from the Dutch polyposis registry. Data on causes of death were collected. Pathology reports were retrieved from the Dutch Pathology Registry.

Results A total of 85 extracolonic malignancies were diagnosed in 74 of 582 APC mutation carriers. Duodenal and skin cancers were the most prevalent cancers. Thyroid cancer was observed in only $1.5 \%$ of the cases. The main cause of death was cancer (59\% of all deaths), with $42 \%$ due to CRC and $21 \%$ due to duodenal cancer. One patient died from thyroid cancer. The second and third most common causes of death were cardiovascular disease (13\% of all deaths) and desmoid tumours (11\% of all deaths), respectively.

Conclusion Extending surveillance programmes to other cancers will not contribute significantly to the survival of patients with FAP.

\section{INTRODUCTION}

Familial adenomatous polyposis (FAP) is an autosomal dominantly inherited disease caused by germline mutations in the adenomatous polyposis coli (APC) gene. ${ }^{1}$ FAP is characterised by the development of hundreds to thousands of colorectal adenomas, and unless prophylactic colectomy is performed the risk of colorectal cancer (CRC) is almost $100 \%$. While nearly all mutation carriers also develop duodenal adenomas, the risk of duodenal cancer is significantly lower, estimated at around $5 \%$ to $15 \% .^{23}$ Less frequently, other extracolonic cancers may be observed such as cancers of the thyroid, brain, stomach, pancreas, liver and desmoid tumours. Desmoid tumours are histologically benign fibroblastic tumours that are locally aggressive but lack metastatic potential.

During the 1980s and 1990s, polyposis registries were established with the aim of promoting participation in colorectal and upper gastrointestinal (GI) surveillance programmes to prevent intestinal cancer. Establishment of these registries has resulted in earlier diagnosis and significant decrease in incidence of CRC, and an increase in the life expectancy of patients with FAP. $^{4-6}$ As a consequence, studies began to report a shift in the causes of death in those patients and today, beside CRC, the main reported causes of death are duodenal cancer and desmoid tumours. $^{78}$

An important and still unanswered question is whether life expectancy of patients with FAP can be further improved by extending existing surveillance programmes to other organs such as the thyroid, stomach, liver or pancreas. Decisions on surveillance of a particular organ should be based on the criteria proposed by Wilson and Jungner. ${ }^{9}$ Most important among these criteria are the following requirements: (1) the disease should be a common manifestation in the target group, (2) available screening tools should be highly sensitive and specific (and not too burdensome), and (3) early treatment should improve the prognosis and increase life expectancy.

Previous studies have reported risks that vary widely for cancers of the thyroid, liver and pancreas in FAP. As a consequence, there is still no consensus regarding the need for additional surveillance recommendations for these cancers.

The aims of this study were (1) to assess the occurrence of extracolonic malignancies and benign tumours in a large series of patients with FAP with a proven APC mutation known from the Dutch polyposis registry and (2) to evaluate whether these extracolonic malignancies are an important cause of death.

\section{PATIENTS AND METHODS \\ Dutch Polyposis Registry}

The Dutch Polyposis Registry was established by the Netherlands Foundation for Detection of Hereditary Tumours (NFDHT) in 1985. The main objective of the registry is to promote early detection of upper and lower GI cancers through coordination of lifelong surveillance of at-risk patients. ${ }^{10}$ Patients with FAP are referred to this national registry by gastroenterologists, surgeons or clinical geneticists. At the time of registration, written informed consent for collection of personal and medical data 
is provided by all patients. At regular intervals (usually annually), the registry sends out reminders to gastroenterologists to prompt patient screening, and the results of these endoscopies and results of histological examinations are then sent to the registry. To date, $>2000$ patients with a clinical diagnosis of FAP have been registered, of which $>500$ are proven APC germline mutation carriers. This study was approved by the research committee of the registry.

\section{Cross-referencing the Dutch Polyposis Registry to the National Pathology Registry}

For this study, we selected all patients with FAP with a proven germline APC mutation in the Dutch polyposis registry. All medical information, age at last follow-up and mortality including cause of death and age at death were collected. The medical files usually contain histology reports of surgical specimens or biopsies. However, to improve the quality of the medical data, we cross-referenced polyposis registry data to the 'nationwide network and registry of histopathology and cytopathology in the Netherlands (PALGA)', which was established in 1971. ${ }^{11}$ The PALGA database does not contain identifying patient data, but only pseudonyms based on this data. Pseudonymisation of the Dutch polyposis registry was carried out by a trusted third party to maintain data confidentiality.

\section{Statistical analysis}

Descriptive statistical analysis was used. Observations were from 1971 or time of registration to death, loss to follow-up or end of the study (1 May 2014). Data were analysed and calculations were carried out using SPSS V.22.0.

\section{RESULTS}

\section{Study population}

A total of 567 proven APC mutation carriers registered at the Dutch Polyposis Registry were enrolled in the study. All included patients were cross-referenced to the PALGA registry. Of those, two patients were excluded due to missing clinical data. An additional search in the polyposis registry identified a further 17 patients with FAP with a confirmed APC mutation who were also included in the study. Using the records of the Dutch Polyposis Registry, the occurrence of extracolonic malignancies was studied in these 17 patients. The total group of patients was 582 (49.7\% male). The mean age at last follow-up was 39.9 years.

\section{Benign extracolonic lesions}

Of the 565 patients initially enrolled in the study, 191 (33.8\%) had at least one pathology report with evidence of duodenal adenomatous polyposis. Fundic gland polyposis was reported in $102(18.1 \%)$ patients, and $24(4.2 \%)$ patients had at least one gastric adenoma, all located in the antrum.

Desmoid tumours confirmed by a histology report were described in $27(4.8 \%)$ of the carriers. A total of 38 patients $(6.7 \%)$ had a benign skin tumour of several types. Lipomas and osteomas were documented in $11(1.9 \%)$ and $7(1.2 \%)$ patients, respectively. Other reported tumours included a benign thyroid tumour (one patient), adrenal tumours (two patients) and ovarian cystadenomas (three patients).

\section{Malignant extracolonic lesions}

A total of 85 extracolonic malignancies were documented by pathology report in 582 APC mutation carriers, and $74(12.7 \%)$ of the carriers had at least one malignant extracolonic lesion.
Table 1 Extracolonic cancers in 582 FAP patients with APC mutation

\begin{tabular}{llll}
\hline Site of cancer & $\mathbf{n}(\%)$ & Gender $(\mathbf{m} / \mathbf{f})$ & $\begin{array}{l}\text { Mean age at } \\
\text { diagnosis (range) }\end{array}$ \\
\hline Duodenum & $18(3.1)$ & $8 / 10$ & $52.1(32-79)$ \\
Skin & $13(2.2)$ & $8 / 5$ & $52.1(26-67)$ \\
Thyroid & $9(1.5)$ & $1 / 8$ & $38.6(19-53)$ \\
Lung & $7(1.2)$ & $4 / 3$ & $50.1(35-61)$ \\
Breast & $6(2.0)^{*}$ & $0 / 6$ & $43.5(33-68)$ \\
Bladder & $4(0.7)$ & $3 / 1$ & $51.5(31-64)$ \\
Hepatoblastoma & $4(0.7)$ & $3 / 1$ & $1.8(1-3)$ \\
Unknown primary & $4(0.7)$ & $3 / 1$ & $42.5(23-55)$ \\
Liver & $3(0.5)$ & $3 / 0$ & $31(17-68)$ \\
Endometrium & $2(0.7)^{*}$ & $0 / 2$ & $44.5(41-48)$ \\
Brain tumour & $2(0.3)$ & $1 / 1$ & $31.0(13-49)$ \\
Meningioma & $2(0.3)$ & $1 / 1$ & $40.0(46-34)$ \\
Pancreas & $2(0.3)$ & $1 / 1$ & $54.5(40-69)$ \\
Others $\dagger$ & $9(1.5)$ & $5 / 4$ & $46.6(26-77)$ \\
\hline
\end{tabular}

*\% calculated in female patients.

tOvary, cervix, vagina, lymphoma, larynx, vocal cords, parotid, prostate, stomach. APC, adenomatous polyposis coli; FAP, familial adenomatous polyposis; $\mathrm{m} / \mathrm{f}$, male/ female.

The frequency of extracolonic malignancies and mean age at diagnosis are shown in table 1.

Duodenal cancer and skin cancers (basal cell carcinoma, squamous cell carcinoma and melanoma) were the most common extracolonic cancers (in $3.1 \%$ and $2.2 \%$ of patients, respectively), followed by thyroid cancer (1.5\%). Six of $294(2.0 \%)$ female patients were diagnosed with breast cancer, at a mean age of 43.5 years. In four of these patients, the breast cancer was diagnosed before 40 years of age.

Thyroid cancer was documented in nine patients $(1.5 \%)$. Seven female patients $(2.4 \%$ of all female patients) were diagnosed with papillary thyroid cancer, with a mean age of 33.5 years at diagnosis. Duodenal cancer was observed in 18 patients including 14 of ampullary origin (3.1\%), hepatoblastoma in 4 $(0.7 \%)$, bladder cancer in $4(0.7 \%)$ and pancreatic malignancy, malignant brain tumour and meningioma were each observed in 2 patients.

\section{Cause of death}

In addition to CRC (25\% of all deaths), extracolonic cancers (33.9\%) and cardiovascular disease $(12.5 \%)$ were the two most common causes of death in Dutch APC mutation carriers. Duodenal cancers and desmoid tumours were responsible for $12.5 \%$ and $10.7 \%$ of deaths, respectively. One patient died from thyroid cancer at the age of 78 years. Two patients died due to complications of Whipple surgery and one patient committed suicide at the age of 36 years. Table 2 describes the causes and age at death in APC mutation carrier patients in the Dutch polyposis registry.

\section{DISCUSSION}

The most common extracolonic cancers found in this study were duodenal cancer and skin tumours. The frequency of other FAP-associated cancers such as cancer of the thyroid, liver (hepatoblastoma), brain and stomach was low. Among the benign lesions, the most frequent were fundic gland polyps, duodenal and gastric adenomas and desmoid tumours. The most prevalent cause of death was cancer (59\%), with $42 \%$ of the cancer deaths due to CRC and $21 \%$ of the cancer deaths due to duodenal cancer. The second and third most common causes of death 
Table 2 Cause of death in patients with APC mutation polyposis

\begin{tabular}{llll}
\hline & $\mathbf{n}(\%)$ & Gender $(\mathbf{m} / \mathbf{f})$ & $\begin{array}{l}\text { Mean age at death } \\
\text { (range) }\end{array}$ \\
\hline CRC & $14(25)$ & $5 / 9$ & $46.8(23.4-65.7)$ \\
\hline $\begin{array}{l}\text { Other cancers* } \\
\text { Cardiovascular }\end{array}$ & $19(33.9)$ & $10 / 9$ & $51.6(33.0-78.4)$ \\
disease & $7(12.3)$ & $6 / 1$ & $68.1(82.3-45.1)$ \\
Desmoid tumour & $6(10.7)$ & $4 / 2$ & $40.5(33.0-49.3)$ \\
Others & $4(7.1)$ & $2 / 2$ & $56.2(30.4-80.2)$ \\
Unknown & $6(10.7)$ & $2 / 4$ & $49.9(36.3-65.0)$ \\
Total & $56(100)$ & $29 / 27$ & $51.2(23.4-82.6)$ \\
\hline *Known FAP association: duodenal cancer (7), pancreatic cancer (2), brain tumour
\end{tabular}

*Known FAP association: duodenal cancer (7), pancreatic cancer (2), brain tumour (1), thyroid cancer (1); not known FAP association: lung cancer (3), unknown primary (2), gastric cancer (1), non-Hodgkin's lymphoma (1), hepatocellular carcinoma (1).

APC, adenomatous polyposis coli; CRC, colorectal cancer; FAP, familial adenomatous polyposis; $\mathrm{m} / \mathrm{f}$, male/female.

were cardiovascular disease (12.5\% of all deaths) and desmoid tumours (10.7\% of all deaths), respectively.

A number of studies have reported frequencies for extracolonic cancers in FAP, but results vary widely. For instance, the prevalence rates of thyroid cancer in the literature vary from $0.4 \%$ to $11.8 \% .^{12-14}$ Reported frequencies appear to depend on the type of study, that is, prospective versus retrospective studies or large registry studies versus small series. The frequencies found in our study were similar to those reported in previous registry-based studies (1\%-2\%). Likewise, the frequencies of brain tumours, pancreatic cancer and hepatoblastoma we observed were also equal to rates reported in the literature at around $<1 \%-2 \% .{ }^{15} 16$

Prevalence of duodenal cancer was relatively low at 3\%, which may be due to upper GI surveillance and the implementation of prophylactic duodenectomy in patients with advanced duodenal polyposis. ${ }^{17}$ In this study, we identified only one patient with gastric cancer, in agreement with earlier studies that showed that the incidence of this cancer is not increased in FAP families in Western countries. By contrast, studies from Japan and South Korea report gastric cancer rates of 3\%-4\%. ${ }^{18} 19$

Although the incidence of other cancers (eg, cancer of lung and breast) was not increased, interestingly, the age of breast cancer diagnosis observed in our patients with polyposis was relatively low.

One of the strengths of this study was that we were able to assemble a very large cohort of proven APC mutation carriers with a follow-up of more than 25 years. In addition, cross-referencing the polyposis registry with the PALGA database allowed us to expand the number of patients with pathologically confirmed tumours.

The limitation of the study was that some extracolonic tumours such as brain tumours and desmoid tumours were not always confirmed by pathology and therefore may have been underestimated. The same is probably true for some benign lesions, such as fundic gland polyps, because the endoscopic appearance of fundic gland polyposis in a patient with FAP is very typical and biopsies for pathological confirmation are often not obtained. Furthermore, the PALGA database was established in 1971 and gradually extended its coverage to $100 \%$ by 1991 . As a consequence, some tumours might have been missed.

What are the implications of this study for clinical practice? The consensus in the current guidelines is that patients should be screened for duodenal adenomas/cancer, in addition to surveillance of the colon. However, consensus has not yet been reached with respect to other non-intestinal cancers, including cancers of the thyroid, pancreas and liver. ${ }^{152021}$

If we apply the above-mentioned criteria developed by Wilson and Jungner to decision-making on thyroid cancer surveillance, we can conclude that the risk of thyroid cancer found in this study and other registry studies is relatively low, with women showing the highest risk. Although highly sensitive screening tools for thyroid cancer like ultrasonography (US) and fine needle aspiration (FNA) biopsy are available, a major disadvantage is that regular examination will frequently reveal benign lesions that result in FNA biopsy. These findings and subsequent biopsies represent a burden for patients and may also cause substantial anxiety. The most important finding of our study was that only one patient died from this cancer, at the age of 78 years. On the basis of these considerations, we do not recommend thyroid cancer surveillance in patients with FAP outside of research programmes.

Regarding the need for liver tumour (hepatoblastoma) surveillance, the prevalence of this type of tumour in our and other studies was very low, at around 1\%. In addition, none of the four patients in our study died as a result from this tumour. Because hepatoblastoma is a disease that occurs in early childhood, a consequence of the decision to screen mutation carriers for these tumours would be that APC mutation analysis would have to be performed at birth rather than from the age of between 10 and 12 years, as is current practice. This change in policy would lead to stigmatisation of children found to be mutation carriers. In view of these considerations, we do not recommend surveillance of mutation carriers for liver tumours outside of research programmes.

Finally, although cancer of the pancreas appears to be associated with FAP, the prevalence is very low and we do not recommend screening.

In conclusion, the life expectancy of patients with FAP has increased substantially following implementation by registries of screening programmes for colorectal and duodenal cancer. On the basis of our data, we conclude that extending these surveillance programmes to extraintestinal-associated cancers will not further improve life expectancy in APC mutation carriers.

\section{Author affiliations}

${ }^{1}$ Department of Gastroenterology \& Hepatology, Leiden University Medical Center, Leiden, The Netherlands

${ }^{2}$ Netherlands Foundation for the Detection of Hereditary Tumors, Leiden, The Netherlands

${ }^{3}$ Department of Gastroenterology and Hepatology, Academic Medical Center, University of Amsterdam, Amsterdam, The Netherlands

${ }^{4}$ Department of Gastroenterology and Hepatology, Radboud University Nijmegen Medical Center, Nijmegen, The Netherlands

${ }^{5}$ Department of Gastroenterology and Hepatology, Erasmus MC, University Medical Center Rotterdam, Rotterdam, The Netherlands

${ }^{6}$ Department of Gastroenterology and Hepatology, University of Groningen,

University Medical Center Groningen, Groningen, The Netherlands

${ }^{7}$ Department of Internal Medicine, Division of Gastroenterology and Hepatology,

Maastricht University Medical Center, Maastricht, The Netherlands

${ }^{8}$ Department of Gastroenterology and Hepatology, Isala Clinics, Zwolle, The

Netherlands

${ }^{9}$ Department of Gastroenterology, Gelderse Vallei Hospital, Ede, The Netherlands

${ }^{10}$ Department of Pathology, Leiden University Medical Center, Leiden, The Netherlands

Acknowledgements This study was supported by NFDHT and PALGA registries.

Contributors Conception and design: ZG, HFAV. Provision of study materials or patients: BAJB, AMJL, FN, J-WP, JCHH, JJK, SS, WHVNC, BJMW, HM, ED. Collection and assembly of data: ZG, HFAV. Data analysis and interpretation: ZG, HFAV. Manuscript writing: All authors. Final approval of manuscript: All authors. 
Funding Study supported by the Netherlands Foundation of Detection of Hereditary Tumours (NFDHT).

Competing interests None declared.

Patient consent Patients registered at the Netherlands Foundation for the Detection of Hereditary Tumors (StOET) sign a consent form approving the use of their medical data for research purposes upon registration.

Ethics approval Approved by boards of the Netherlands Foundation for the Detection of Hereditary Tumors (StOET) and the nationwide network and registry of histo- and cytopathology in the Netherlands (PALGA).

Provenance and peer review Not commissioned; externally peer reviewed.

(c) Article author(s) (or their employer(s) unless otherwise stated in the text of the article) 2018. All rights reserved. No commercial use is permitted unless otherwise expressly granted.

\section{REFERENCES}

1 Bodmer WF, Bailey CJ, Bodmer J, Bussey HJ, Ellis A, Gorman P, Lucibello FC, Murday VA, Rider SH, Scambler P. Localization of the gene for familial adenomatous polyposis on chromosome 5. Nature 1987;328:614-6.

2 Björk J, Akerbrant H, Iselius L, Bergman A, Engwall Y, Wahlström J, Martinsson T, Nordling M, Hultcrantz R. Periampullary adenomas and adenocarcinomas in familial adenomatous polyposis: cumulative risks and APC gene mutations. Gastroenterology 2001;121:1127-35.

3 Bülow S, Björk J, Christensen IJ, Fausa O, Järvinen H, Moesgaard F, Vasen HF; DAF Study Group. Duodenal adenomatosis in familial adenomatous polyposis. Gut 2004:53:381-6.

4 Bülow S, Bülow C, Nielsen TF, Karlsen L, Moesgaard F. Centralized registration, prophylactic examination, and treatment results in improved prognosis in familial adenomatous polyposis. results from the danish Polyposis Register. Scand I Gastroenterol 1995;30:989-93.

5 Vasen HF, Griffioen G, Offerhaus GJ, Den Hartog Jager FC, Van Leeuwen-Cornelisse IS, Meera Khan P, Lamers CB, Van Slooten EA. The value of screening and central registration of families with familial adenomatous polyposis. A study of 82 families in the Netherlands. Dis Colon Rectum 1990;33:227-30.

6 Bülow S. Results of national registration of familial adenomatous polyposis. Gut 2003;52:742-6.

7 de Campos FG, Perez RO, Imperiale AR, Seid VE, Nahas SC, Cecconello I. Evaluating causes of death in familial adenomatous polyposis. J Gastrointest Surg 2010;14:1943-9.

8 Nugent KP, Spigelman AD, Phillips RK. Life expectancy after colectomy and ileorectal anastomosis for familial adenomatous polyposis. Dis Colon Rectum 1993:36:1059-62.

9 Wilson JM, Jungner YG. Principles and practice of mass screening for disease. Bol Oficina Sanit Panam 1968;65:281-393.

10 Vasen HF, Velthuizen ME, Kleibeuker JH, Menko FH, Nagengast FM, Cats A, van der Meulen-de Jong AE, Breuning MH, Roukema AJ, van Leeuwen-Cornelisse I, de Vos
Tot Nederveen Cappel WH, Wijnen JT. Hereditary cancer registries improve the care of patients with a genetic predisposition to cancer: contributions from the Dutch Lynch syndrome registry. Fam Cancer 2016;15:429-35.

11 Casparie M, Tiebosch AT, Burger G, Blauwgeers H, van de Pol A, van Krieken JH, Meijer GA. Pathology databanking and biobanking in the Netherlands, a central role for PALGA, the nationwide histopathology and cytopathology data network and archive. Cell Oncol 2007;29:19-24.

12 van der Linde K, Vasen HF, van Vliet AC. Occurrence of thyroid carcinoma in dutch patients with familial adenomatous polyposis. an epidemiological study and report of new cases. Eur J Gastroenterol Hepatol 1998;10:777-82.

13 Herraiz M, Barbesino G, Faquin W, Chan-Smutko G, Patel D, Shannon KM, Daniels GH, Chung DC. Prevalence of thyroid cancer in familial adenomatous polyposis syndrome and the role of screening ultrasound examinations. Clin Gastroenterol Hepatol 2007:5:367-73.

14 Giardiello FM, Offerhaus GJ, Lee DH, Krush AJ, Tersmette AC, Booker SV, Kelley NC, Hamilton SR. Increased risk of thyroid and pancreatic carcinoma in familial adenomatous polyposis. Gut 1993;34:1394-6.

15 Syngal S, Brand RE, Church JM, Giardiello FM, Hampel HL, Burt RW. American College of Gastroenterology. ACG clinical guideline: genetic testing and management of hereditary gastrointestinal cancer syndromes. Am J Gastroenterol 2015;110:223-62.

16 Groen EJ, Roos A, Muntinghe FL, Enting RH, de Vries J, Kleibeuker JH, Witjes MJ, Links TP, van Beek AP. Extra-intestinal manifestations of familial adenomatous polyposis. Ann Surg Oncol 2008;15:2439-50.

17 van Heumen BW, Nieuwenhuis MH, van Goor H, Mathus-Vliegen LE, Dekker E, Gouma DJ, Dees J, van Eijck CH, Vasen HF, Nagengast FM. Surgical management for advanced duodenal adenomatosis and duodenal cancer in Dutch patients with familial adenomatous polyposis: a nationwide retrospective cohort study. Surgery 2012;151:681-90.

18 Yamaguchi T, Ishida H, Ueno H, Kobayashi H, Hinoi T, Inoue Y, Ishida F, Kanemitsu Y, Konishi T, Tomita N, Matsubara N, Watanabe T, Sugihara K. Upper gastrointestinal tumours in japanese familial adenomatous polyposis patients. Jpn I Clin Oncol 2016:46:310-5.

19 Park SY, Ryu JK, Park JH, Yoon H, Kim JY, Yoon YB, Park JG, Lee SH, Kang SB, Park $\mathrm{JW}, \mathrm{Oh} \mathrm{JH}, \mathrm{Jh} \mathrm{O}$. Prevalence of gastric and duodenal polyps and risk factors for duodenal neoplasm in korean patients with familial adenomatous polyposis. Gut Liver 2011;5:46-51.

20 Stoffel EM, Mangu PB, Gruber SB, Hamilton SR, Kalady MF, Lau MW, Lu KH, Roach $\mathrm{N}$, Limburg PJ. American Society of Clinical OncologyEuropean Society of Clinical Oncology. Hereditary colorectal cancer syndromes: American society of clinical oncology clinical practice guideline endorsement of the familial risk-colorectal cancer: European society for medical oncology clinical practice guidelines. I Clin Oncol 2015;33:209-17.

21 Provenzale D, Gupta S, Ahnen DJ, Bray T, Cannon JA, Cooper G, David DS, Early DS, Erwin D, Ford JM, Giardiello FM, Grady W, Halverson AL, Hamilton SR, Hampe H, Ismail MK, Klapman JB, Larson DW, Lazenby AJ, Lynch PM, Mayer RJ, Ness RM, Regenbogen SE, Samadder NJ, Shike M, Steinbach G, Weinberg D, Dwyer M, Darlow S. Genetic/Familial High-Risk Assessment: colorectal version 1.2016, NCCN Clinical Practice guidelines in Oncology. J Nat/ Compr Canc Netw 2016;14:1010-30. 


\section{JMG}

\section{Extracolonic cancer risk in Dutch patients with APC (adenomatous polyposis coli)-associated polyposis}

Zeinab Ghorbanoghli, Barbara AJ Bastiaansen, Alexandra MJ Langers, Fokko M Nagengast, Jan-Werner Poley, James CH Hardwick, Jan J Koornstra, Silvia Sanduleanu, Wouter $\mathrm{H}$ de Vos tot Nederveen Cappel, Ben JM Witteman, H Morreau, Evelien Dekker and Hans FA Vasen

J Med Genet2018 55: 11-14 originally published online May 10, 2017 doi: 10.1136/jmedgenet-2017-104545

Updated information and services can be found at:

http://jmg.bmj.com/content/55/1/11

\section{These include:}

References This article cites 21 articles, 5 of which you can access for free at: http://jmg.bmj.com/content/55/1/11\#ref-list-1

Email alerting service

Receive free email alerts when new articles cite this article. Sign up in the box at the top right corner of the online article.

\section{Notes}

To request permissions go to:

http://group.bmj.com/group/rights-licensing/permissions

To order reprints go to:

http://journals.bmj.com/cgi/reprintform

To subscribe to BMJ go to:

http://group.bmj.com/subscribe/ 